\title{
Prophylaxis and treatment of cystoid macular edema after cataract surgery
}

\author{
Profilaxia e tratamento do edema macular \\ cistoide após cirurgia de catarata
}

Pedro C. Carricondo', Maria Fernanda Abalem², Cleide Guimarães Machado ${ }^{3}$, Newton Kara-Junior ${ }^{4}$

\begin{abstract}
Macular cystoid edema is one of the major causes of decreased vision after cataract surgery. The inflammatory process appears to be the main causal factor of the edema. The major risk factors are: surgical complications, previous retinal diseases, diabetes, uveitis and use of prostaglandins drops. The diagnosis is clinically, but fluorescein angiography and optical coherence tomography are also important to detect swelling and assist in differential diagnosis. Although pre-operative prophylaxis do not have scientific evidence, it is recommended especially in cases with risk factors. The initial treatment includes a combination of both topic corticosteroid and nonsteroidal anti-inflammatory. Chronic and refractory cases can be managed with alternatives treatment, such as intravitreal triamcinolone and anti-angiogenic. This article aims to discuss various aspects of pseudophakic macular cystoid edema.

Keywords: Macular edema; Phacoemulsification; Anti-inflammatory agents, non-steroidal; Steroids; Vascular endothelial growth factors
\end{abstract}

\section{RESUMO}

O edema macular cistoide é uma das principais causas de baixa de visão após cirurgia de catarata. O processo inflamatório parece ser o principal fator causal do edema. São considerados fatores de risco complicações cirúrgicas, doenças retinianas prévias, diabetes, uveítes e uso de colírios de prostaglandinas. $O$ diagnóstico é feito clinicamente, mas a angiografia fluoresceínica e a tomografia de coerência óptica também são ferramentas importantes para detectar o edema e auxiliar no diagnóstico diferencial. Apesar da profilaxia préoperatória não ter evidência científica, ela é preconizada especialmente nos casos com fatores de risco. O tratamento inicial é realizado com associação de corticoide e anti-inflamatório não hormonais tópicos. Os casos crônicos e refratários têm diversas alternativas de tratamento, sendo o uso de triancinolona e antiangiogênicos intravítreos as mais utilizadas. Este artigo se propõe a discutir diversos aspectos do edema macular cistoide pseudofácico.

Descritores: Edema macular; Facoemulsificação; Anti-inflamatórios, não esteroides; Esteroides; Fatores de crescimento do endotélio vascular

\footnotetext{
1 Retina and Cataract Divisions, Hospital das Clínicas, Medical School, University of São Paulo. São Paulo, SP, Brasil.

2 Retina Division, Hospital das Clínicas, Medical School, University of São Paulo. São Paulo, SP, Brasil.

${ }^{3}$ Retina Division, Hospital das Clínicas, Medical School, University of São Paulo. São Paulo, SP, Brasil.

${ }^{4}$ Graduate Program, Medical School, University of São Paulo. São Paulo, SP, Brasil.
}

The authors declare no conflict of interest.

Received for publication 20/05/2013 - Accepted for publication 16/11/2013. 


\section{INTRODCTION}

$\mathbf{T}$ The pseudophakic macular cystoid edema, also known as Irvine Gass syndrome, is one of the possible causes for low visual acuity after cataract surgery. Despite advances in cataract surgery, such as microincision and new phacoemulsification techniques, CME may occur even in uncomplicated surgeries(1).

CME may be considered angiographic when observed via fluorescein angiography or clinical when there is low visual acuity. American studies show that angiographic edema may occur in $60 \%$ of intracapsular surgeries, varying between $15-30 \%$ in extracapsular (2)surgeries and $4-11 \%$ in phacoemulsification(3, 4). Clinical CME, on the other hand, occurs in only 0.1 to $2.35 \%$ of patients(5).

In times of premium intraocular lenses, intraoperative aberrometry, laser-guided surgery and economically active patients, expectations of perfect vision and fast recovery have increased significantly. Therefore, reduced visual acuity due to CME is not tolerated well by either patients or surgeons.

\section{Pathogenesis and Risk Factors}

CME pathogenesis remains unkown, but several factors have already been involved, such as inflammation, vascular instability, vitreomacular traction, ocular hypotonia and harm by exposure to ultraviolet light(5). Inflammation due to surgical manipulation seems to be the main cause(6). Inflammatory mediators increase vascular permeability and transudates accumulate in the external plexiform layer and inner nuclear layer, forming cysts(1).

CME incidence increases when surgical complications occur (5). Prominent among these are the posterior capsular rupture, vitreous loss, incarcerated vitreous in the incision, cortical remnants in the vitreous, trauma to the iris, intraocular lens dislocation, iris fixation or anterior layer intraocular lens and premature posterior capsulotomy $(1,7)$.

Pre-existing retinal diseases such as retinal vein occlusion and vitreoretinal interface changes, such as the epiretinal membrane, pose a bigger risk of CME (5). Special attention must be paid to diabetic patients (5). In these cases, it is extremely difficult to differentiate between CME and diabetic macular edema (8), since diabetic macular edema patients tend to have worse vision after cataract surgery. Patients with prior treated macular edema, regardless of treatment choice, and patients with non central-involved macular edema are at greater risk of worsening conditions (8), although there is controversy regarding the risk of diabetic retinopathy progression (9). For practical purposes, patients suffering from central-involved or non central-involved macular edema, history of previously treated macular edema and severe retinopathy should be properly treated before surgery(8).

Patients with uveitis are also more likely to develop CME compared to normal patients $(3,5)$. Strict control of the inflammation is advisable before surgery, as well as greater attention during the postoperative phase for possible prophylaxis use (10).

In glaucoma patients, the use of prostaglandin drops is linked to a higher incidence of CME. It is believed that bimatoprost, latanoprost and travoprost break the bloodaqueous barrier, causing edema formation. Besides these drugs, benzalkonium chloride, a preservative frequently used in eye drops, also contributes to $\operatorname{CME}(5,11)$.

\section{Diagnosis and differential diagnosis}

Clinical CME appears on average from 4 to 6 weeks after surgery. Most patients present with loss of visual acuity and macular thickening, which can be seen by posterior segment biomicroscopy.

Fluorescein angiography can help by showing perifoveal capillary leakage (flower-petal pattern) at the early stages, as well as telangectasias and capillary dilation. Optic nerve impregnation is frequent and extremely important in the differential diagnosis of other causes of CME (12).

Optical coherence tomography (OCT) use has been widespread and its sensitivity works well in detecting macular edema. This test can show hyporeflexia lesions compatible with intraretinal fluid, loss of foveal depression and retinal thickening. OCT is also used to show other changes in the vitreoretinal interface, such as epiretinal membranes and lamellar holes, which may influence the prognosis $(13,14)$.

It is worth noting that fluorescein angiography remains the golden standard on pseudophakic CME diagnosis.

Differential diagnosis for pseudophakic CME is comprehensive and includes: edema secondary to diabetes, retinal venous occlusions, uveitis, radiation retinopathy and choroidal tumors. In elderly patients, it is also important to differentiate pseudophakic CME from a possible sub retinal neovascular membrane secondary to macular degeneration related to age (1). A good preoperative assessment is crucial and helps diagnosis and treatment of such cases.

\section{Prophylaxis}

With the advancement of surgical technique and the improvement of surgical outcome, one of the main concerns for surgeons is to avoid or treat CME in pseudophakic patients (5, 15-17). Atraumatic surgery itself may be considered a prophylactic measure for edema (18).

It is difficult to establish an evidence-based conduct for prophylaxis and therapy of this situation, since there aren't many high level evidence studies in literature, with randomization, control groups and proper number of patients $(15,19)$. The study of this disease is made difficult by controversies regarding pathogenesis, definition, diagnostic criteria and additional tests for postoperative CME (19).

Several studies have been trying to show the effectiveness of prophylactic treatment with topical nonsteroidal antiinflammatory drugs (NSAIDs) in preventing $\operatorname{CME}(20,21)$. In fact, there are statistically significant differences when taking into consideration a decrease in macular thickness measurements (20) and signs of possible edema in OCT (22). However, the main issue is to give those differences clinical significance, since most patients don't develop an edema with clinical repercussion, that is, they don't suffer low visual acuity because of the disease (22). Changes to the blood-retinal barrier occur in almost every operated patient, with an increase in retinal thickness according to OCT in over $40 \%$ of all patients (23). Most patients don't suffer from decreased visual acuity and there is no statistical difference with prophylactic treatment when comparing different drugs (21). Even when theoretically 
more sensitive measures are considered, other than visual acuity, such as sensitivity to contrast, there are no statistically significant differences with prophylactic treatment, although a smaller increase in macular thickness and smaller loss of sensitivity to contrast have occurred (22).

Prophylaxis must be considered especially for patients with risk factors, especially uveitis (3), diabetes (24), cardiovascular diseases (5), venous retinal occlusions (5) and intraoperative complications, such as posterior capsular rupture and vitreous loss $(17,20,23)$. Extracapsular cataract extractions or cases where phacoemulsification was not successful should also be especially examined regarding the development of cystoid macular edema and receive prophylaxis $(20,23)$.

Another group that seems to need medical prophylaxis of cystoid edema is that of patients who take drugs for glaucoma, especially prostaglandin/prostamide analogues (11, 20, 25, 26). Other drugs may be related to an increase in post-surgery edema incidence, such as phenylephrine, pilocarpine, timolol, betaxolol and other drops which use benzalkonium chloride as a preservative $(5,27,28)$.

In diabetic patients, macular edema is the main cause for low visual acuity after cataract surgery $(17,24)$. The incidence in these patients is $22 \%$ and it is correlated to lower visual acuity (24). An early diagnosis is important in these cases, because there is evidence that when treatment is delayed, even after treating the edema, visual acuity may not be recovered (24).

The use of NSAIDs with the usual postoperative corticosteroid treatment worked better in reducing CME detected by OCT when compared to just corticosteroids (29, 30). Ketorolac tromethamine has proved effective in reducing macular thickening in postoperative follow up to cataract surgery (25), which could guarantee better results, especially for lenses which demand more from the visual system, such as multifocals. Nonetheless, it was not possible to show statistically significant differences in the prevention of macular edema with clinical implications (21), that is, with a loss of visual acuity (19), even with other drugs, such as nepafenac (31). Other NSAIDs not currently available in Brazil, such as flurbiprofen and indomethacin, were tested with favorable results in reducing the onset of angiographic CME(29).

Postoperative prophylactic use of topical NSAIDs has shown to be effective in preventing CME in high risk groups, particularly diabetics and surgery with intraoperative complications. Patients using prophylaxis have not shown a higher level of edema $(5,29)$.

The use of preoperative topical NSAIDs, beyond a prophylactic effect regarding cystoid macular edema, also tries to reduce perioperative miosis $(19,29)$, pain (29) and postoperative photophobia (29). The improval of mydriasis and/or reduction of miosis has not been confirmed by us, compared to other preoperative schemes for mydriasis optimization (32).

\section{Treatment}

The aim of treatment is to contain the inflammatory cascade which leads to blood-retinal barrier, resulting in intraretinal fluid accumulation $(5,22,33)$. It is worth noting that after 30 weeks, up to $50 \%$ of patients have angiographic alterations in the fundus and $30 \%$ have edema according to OCT (23).

There is evidence that the inflammatory process is exacerbated in patients with macular edema, with anterior layer inflammation measurements more than 2.5 times higher than operated eyes with no edema, with a correlation between the inflammatory process and visual acuity (18). This observation is also true in patients that undergo vitrectomy before cataract surgery, and may predict whether edema will occur (18).

Treatment should begin by removing post-surgical factors predisposing to $\mathrm{CME}$, such as anterior layer lens, possible vitreous wick with traction $(17,34)$ and even lenses sitting in the groove, possibly causing friction against the iris (17).

Most cases are spontaneously solved, even without treatment $(5,33)$. However, it is not possible to predict which cases will become chronic and should be treated as acute (up to 4 months after onset) (33) and which could go untreated (5).

Anti-inflammatory drugs, both steroidal (corticosteroids) and non-steroidal, are effective in treating $\operatorname{CME}(5,20,33)$, reducing its duration and severity(16). Treatment reduces macular thickening and improves visual acuity, although the low incidence of cases with loss of visual acuity makes it harder to carry out studies with a higher level of evidence $(15,20)$.

Measuring anterior layer inflammation may help to monitor the possibility of edema onset and response to treatment, adjusting treatment according to the inflammatory response (18).

Both topical treatment with NSAIDs and with corticosteroids seem to increase the rate of CME improvement compared to the untreated patients group (5). The combination of both drugs seem to have a better effect than each one by itself, both in rate of improvement and in gain of vision and contrast sensitivity (33). NSAIDs act by inhibiting cyclooxygenases (COX) 1 and 2, while corticosteroids inhibit COX 2 (5) lipooxygenases, thereby boosting their effect, so they can be combined (33). In general, no difference in visual acuity were observed with each class used individually or combined (5).

The most commonly used corticosteroids for CME treatment and prevention are: prednisolone (topical), dexamethasone (topical and intravitreal implant), fluorometholone (topical) and triamcinolone (intravitreal). The most commonly used topical NSAIDs are diclofenac, ketorolac tromethamine, bromfenac, flurbiprofen, indomethacin and nepafenac (29), not all of them available in Brazil. Topical corticosteroids are used not only as therapy but also as therapeutic test for intraocular pressure response for a possible peri or intraocular corticosteroid injection (33).

Among steroidal anti-inflammatory drugs, fluoromet holone seems less effective in preventing and treating cystoid edema detected by angiography than NSAIDs (35).

Betamethasone was used as sub-Tenon injection for treating chronic CME, with good anecdotal results (36). An alternative reported for chronic cases is the long-acting intravitreal dexamethasone implant $(37,38)$. Triamcinolone administered in intravitreal injections is the main option for treating chronic cases which are not responding to the traditional treatment of topical corticosteroid combined with NSAID (17, 39-41). Results are generally satisfactory, though injections may need to be repeated (40). 
Among NSAIDs, ketorolac tromethamine has proved effective in treating chronic CME (42), in a literature review (5) and in double-blind placebo-controlled trials $(43,44)$. This drug has also proved effective in treating acute CME (33). There is not enough evidence about subclinical CME treatment, that is, without loss of visual acuity (5). Diclofenac results were comparable to ketorolac in reducing the duration and severity of acute cystoid edema (45).There are also reports showing nepafenac effectiveness in CME treatment, both acute and chronic (16), despite the fact that there are no comparative studies to other drugs specifically regarding CME (46).

The duration of topical treatment is still disputed, and it is usually prescribed from 4 to 12 weeks $(5,29)$. However, treatment effectiveness is questioned in treatments less than one month long (33). Relapses may occur when treatment is suspended (33). There are reports about the need for longterm NSAID use or even continuous use in cases of late CME diagnosis (42).

Antiantiogenic agents are becoming more popular, with several new indications. One such application is the treatment of chronic CME, aiming to reduce vascular permeability caused by the inflammatory process. Results were favorable, with at least partial recovery of visual acuity and decrease in macular thickness (47-50). Despite limitations related to the study's design, especially the lack of a control group, this is a treatment that deserves attention and should be considered as an option in cases which resist traditional treatments.

The use of systemic carbonic anhydrase inhibitors (acetazolamide) has been suggested, and good results were documented $(17,51)$, despite known systemic side effects (34). A possible alternative is the use of topical carbonic anhydrase inhibitors, suggested for treating edema in several other retina diseases (52), but not yet studied.

Intravitreal octreotide has been used in slow release formulation (34) for patients with chronic CME. It is difficult to compare chronic edema treatments, since beyond the low incidence of the edema itself, only a small portion of patients do not respond to the usual treatments with corticosteroids and topical nonhormonal anti-inflammatory drugs (34).

Several other treatments have been suggested as alternatives in case of resistance to drug-based treatment, but there are only reports of series of cases with no control groups. Laser grid treatment $(53,54)$, intravitreal pegaptanib $(49,55)$ and intravitreal infliximab (56) are examples of treatments that have been attempted with some benefit. Vitreous implication in the edema pathogenesis is disputed, but in selected cases its removal by vitrectomy may be an effective alternative $(7,20,41,57)$.

In summary, treatment should be applied when there is loss of visual acuity, and evidences point to a combination of corticosteroids and topical nonsteroidal anti-inflammatory drugs as the most effective way to solve the edema (33), maintaining the NSAID for a long period. In chronic cases and those unresponsive to usual treatment, intravitreal corticosteroid injections or antiantiogenic agents have proved useful in a significant number of reports. Finally, prophylactic use of NSAIDs is still disputed for normal patients and should be applied to patients at high risk for CME.

\section{RefERENCES}

1. Yonekawa Y, Kim IK. Pseudophakic cystoid macular edema. Curr Opin Ophthalmol. 2012;23(1):26-32.

2. Flach AJ. The incidence, pathogenesis and treatment of cystoid macular edema following cataract surgery. Trans Am Ophthalmol Soc. 1998;96:557-634.

3. Belair ML, Kim SJ, Thorne JE, Dunn JP, Kedhar SR, Brown DM, et al. Incidence of cystoid macular edema after cataract surgery in patients with and without uveitis using optical coherence tomography. Am J Ophthalmol. 2009;148(1):128-35 e2.

4. Perente I, Utine CA, Ozturker C, Cakir M, Kaya V, Eren H, et al. Evaluation of macular changes after uncomplicated phacoemulsification surgery by optical coherence tomography. Curr Eye Res. 2007;32(3):241-7.

5. Henderson BA, Kim JY, Ament CS, Ferrufino-Ponce ZK, Grabowska A, Cremers SL. Clinical pseudophakic cystoid macular edema. Risk factors for development and duration after treatment. J Cataract Refract Surg. 2007;33(9):1550-8.

6. Benitah NR, Arroyo JG. Pseudophakic cystoid macular edema. Int Ophtalmol Clin. 2010;50(1):139-53.

7. Cohen SM, Davis A, Cukrowski C. Cystoid macular edema after pars plana vitrectomy for retained lens fragments. J Cataract Refract Surg. 2006;32(9):1521-6.

8. Diabetic Retinopathy Clinical Research Network Authors/Writing C, Baker CW, Almukhtar T, Bressler NM, Glassman AR, Grover S, et al. Macular edema after cataract surgery in eyes without preoperative central-involved diabetic macular edema. JAMA Ophthalmol. 2013;131(7):870-9.

9. Rashid S, Young LH. Progression of diabetic retinopathy and maculopathy after phacoemulsification surgery. Int Ophtahlmol Clin. 2010;50(1):155-66.

10. Ram J, Gupta A, Kumar S, Kaushik S, Gupta N, Severia S. Phacoemulsification with intraocular lens implantation in patients with uveitis. J Cataract Refract Surg. 2010;36(8):1283-8.

11. Arcieri ES, Santana A, Rocha FN, Guapo GL, Costa VP. Bloodaqueous barrier changes after the use of prostaglandin analogues in patients with pseudophakia and aphakia: a 6-month randomized trial. Arch Ophtahlmol. 2005;123(2):186-92.

12. Kusbeci T, Eryigit L, Yavas G, Inan UU. Evaluation of cystoid macular edema using optical coherence tomography and fundus fluorescein angiography after uncomplicated phacoemulsification surgery. Curr Eye Res. 2012;37(4):327-33.

13. Bonanomi MT, Nicoletti AG, Carricondo PC, Buzalaf F, KaraJose N, Jr., Gomes AM, et al. Retinal thickness assessed by optical coherence tomography (OCT) in pseudophakic macular edema. Arq Bras Oftalmol. 2006;69(4):539-44.

14. Brar M, Yuson R, Kozak I, Mojana F, Cheng L, Bartsch DU, et al. Correlation between morphologic features on spectral-domain optical coherence tomography and angiographic leakage patterns in macular edema. Retina. 2010;30(3):383-9.

15. Rossetti L, Chaudhuri J, Dickersin K. Medical prophylaxis and treatment of cystoid macular edema after cataract surgery. The results of a meta-analysis. Ophthalmology. 1998;105(3):397-405.

16. Hariprasad SM, Callanan D, Gainey S, He YG, Warren K. Cystoid and diabetic macular edema treated with nepafenac $0.1 \%$. J Ocul Pharmacol Ther. 2007;23(6):585-90.

17. Lobo C. Pseudophakic cystoid macular edema. Ophthalmologica Journal international d'ophtalmologie. Int J Ophthalmol. 2012;227(2):61-7.

18. Ersoy L, Caramoy A, Ristau T, Kirchhof B, Fauser S. Aqueous flare is increased in patients with clinically significant cystoid macular oedema after cataract surgery. Br J Ophthalmol. 2013;97(7):862-5. 
19. Kim SJ, Belair ML, Bressler NM, Dunn JP, Thorne JE, Kedhar SR, et al. A method of reporting macular edema after cataract surgery using optical coherence tomography. Retina. 2008;28(6):870-6.

20. Rossetti L, Autelitano A. Cystoid macular edema following cataract surgery. Curr Opin Ophthalmol. 2000;11(1):65-72.

21. Almeida DR, Khan Z, Xing L, Bakar SN, Rahim K, Urton T, et al. Prophylactic nepafenac and ketorolac versus placebo in preventing postoperative macular edema after uneventful phacoemulsification. J Cataract Refract Surg. 2012;38(9):1537-43.

22. Wittpenn JR, Silverstein S, Heier J, Kenyon KR, Hunkeler JD, Earl M, et al. A randomized, masked comparison of topical ketorolac $0.4 \%$ plus steroid vs steroid alone in low-risk cataract surgery patients. Am J Ophthalmol. 2008;146(4):554-60.

23. Lobo CL, Faria PM, Soares MA, Bernardes RC, Cunha-Vaz JG. Macular alterations after small-incision cataract surgery. J Cataract Refract Surg. 2004;30(4):752-60.

24. Kim SJ, Equi R, Bressler NM. Analysis of macular edema after cataract surgery in patients with diabetes using optical coherence tomography. Ophthalmology. 2007;114(5):881-9.

25. Almeida DR, Johnson D, Hollands H, Smallman D, Baxter S, Eng KT, et al. Effect of prophylactic nonsteroidal antiinflammatory drugs on cystoid macular edema assessed using optical coherence tomography quantification of total macular volume after cataract surgery. J Cataract Refract Surg. 2008;34(1):64-9.

26. Esquenazi S. Cystoid macular edema in a pseudophakic patient after switching from latanoprost to BAK-free travoprost. J Ocul Pharmacol Ther. 2007;23(6):567-70.

27. Law SK, Kim E, Yu F, Caprioli J. Clinical cystoid macular edema after cataract surgery in glaucoma patients. J Glaucoma. 2010;19(2):100-4.

28. Feibel RM. Glaucoma as a possible risk factor for the development of pseudophakic cystoid macular edema. J Cataract Refract Surg. 2008;34(5):717-8; author reply 8.

29. O'Brien TP. Emerging guidelines for use of NSAID therapy to optimize cataract surgery patient care. Curr Med Res Opin. 2005;21(7):1131-7.

30. Wolf EJ, Braunstein A, Shih C, Braunstein RE. Incidence of visually significant pseudophakic macular edema after uneventful phacoemulsification in patients treated with nepafenac. J Cataract Refract Surg. 2007;33(9):1546-9.

31. Mathys KC, Cohen KL. Impact of nepafenac $0.1 \%$ on macular thickness and postoperative visual acuity after cataract surgery in patients at low risk for cystoid macular oedema. Eye. 2010;24(1):90-6.

32. Dellape R, Jr., Fortes AC, Avakian A, Kara Jose N, Santos VH, Carricondo PC. Prospective Comparison Of Pupil Dilatation For Cataract Surgery Using Tropicamide Associated To Phenylephrine, Cyclopentolate, Ketorolac Tromethamine Or Saline Solution. Invest Ophthalmol Vis Sci. 2011;52(6):4709-.

33. Heier JS, Topping TM, Baumann W, Dirks MS, Chern S. Ketorolac versus prednisolone versus combination therapy in the treatment of acute pseudophakic cystoid macular edema. Ophthalmology. 2000;107(11):2034-8; discussion 9.

34. Shah SM, Nguyen QD, Mir HS, Polito A, Hafiz G, Tatlipinar S, et al. A randomized, double-masked controlled clinical trial of Sandostatin long-acting release depot in patients with postsurgical cystoid macular edema. Retina. 2010;30(1):160-6.

35. Miyake K. Nonsteroidal anti-inflammatory agents in cataract intraocular lens surgery. Curr Opin Ophthalmol. 1995;6(1):62-5.

36. Randazzo A, Vinciguerra P. Chronic macular edema medical treatment in Irvine-Gass syndrome: case report. Eur J Ophthalmol. 2010;20(2):462-5.

37. Meyer LM, Schonfeld CL. Cystoid macular edema after complicated cataract surgery resolved by an intravitreal dexamethasone 0.7-mg implant. Case Rep Ophthalmol. 2011;2(3):319-22.
38. Brynskov T, Laugesen CS, Halborg J, Kemp H, Sorensen TL. Longstanding refractory pseudophakic cystoid macular edema resolved using intravitreal $0.7 \mathrm{mg}$ dexamethasone implants. Clin Ophthalmol. 2013;7:1171-4.

39. Koutsandrea C, Moschos MM, Brouzas D, Loukianou E, Apostolopoulos M, Moschos M. Intraocular triamcinolone acetonide for pseudophakic cystoid macular edema: optical coherence tomography and multifocal electroretinography study. Retina. 2007;27(2):159-64.

40. Karacorlu M, Ozdemir H, Karacorlu S. Intravitreal triamcinolone acetonide for the treatment of chronic pseudophakic cystoid macular oedema. Acta Ophthalmol Scand. 2003;81(6):648-52.

41. Sevim MS, Sanisoglu H, Turkyilmaz K. Intravitreal triamcinolone acetonide versus pars plana vitrectomy for pseudophakic cystoid macular edema. Curr Eye Res. 2012;37(12):1165-70.

42. Weisz JM, Bressler NM, Bressler SB, Schachat AP. Ketorolac treatment of pseudophakic cystoid macular edema identified more than 24 months after cataract extraction. Ophthalmology. 1999;106(9):1656-9.

43. Flach AJ, Dolan BJ, Irvine AR. Effectiveness of ketorolac tromethamine $0.5 \%$ ophthalmic solution for chronic aphakic and pseudophakic cystoid macular edema. Am J Ophthalmol. 1987;103(4):479-86.

44. Flach AJ, Jampol LM, Weinberg D, Kraff MC, Yannuzzi LA, Campo $\mathrm{RV}$, et al. Improvement in visual acuity in chronic aphakic and pseudophakic cystoid macular edema after treatment with topical $0.5 \%$ ketorolac tromethamine. Am J Ophthalmol. 1991;112(5):514-9.

45. Rho DS. Treatment of acute pseudophakic cystoid macular edema: Diclofenac versus ketorolac. J Cataract Refract Surg. 2003;29(12):2378-84.

46. Duong HV, Westfield KC, Chalkley TH. Ketorolac tromethamine LS $0.4 \%$ versus nepafenac $0.1 \%$ in patients having cataract surgery. Prospective randomized double-masked clinical trial. J Cataract Refract Surg. 2007;33(11):1925-9.

47. Arevalo JF, Maia M, Garcia-Amaris RA, Roca JA, Sanchez JG, Berrocal $\mathrm{MH}$, et al. Intravitreal bevacizumab for refractory pseudophakic cystoid macular edema: the Pan-American Collaborative Retina Study Group results. Ophthalmology. 2009;116(8):1481-7, 7 e1.

48. Diaz-Llopis M, Amselem L, Cervera E, Garcia-Delpech S, Torralba C, Montero J. [Intravitreal injection of bevacizumab for pseudophakic cystoid macular edema resistant to steroids]. Arch Soc Esp Oftalmol. 2007;82(7):447-50.

49. Cervera E, Diaz-Llopis M, Udaondo P, Garcia-Delpech S. Intravitreal pegaptanib sodium for refractory pseudophakic macular oedema. Eye (Lond). 2008;22(9):1180-2.

50. Demirel S, Batioglu F, Ozmert E. Intravitreal ranibizumab for the treatment of cystoid macular edema in Irvine-Gass syndrome. J Ocul Pharmacol Ther. 2012;28(6):636-9.

51. Catier A, Tadayoni R, Massin P, Gaudric A. [Advantages of acetazolamide associated with anti-inflammatory medications in postoperative treatment of macular edema]. J Fran Ophtalmol. 2005;28(10):1027-31.French.

52. Carricondo PC, Abalem MF. Uso dos inibidores tópicos da anidrase carbônica nas doenças retinianas. Retina e Vítreo. 2013(32):24-9.

53. Perez R, Panesso JL, Provenzano J, Vazquez LA, Munoz D. Argon laser photocoagulation for chronic clinically significant cystoid macular edema. P R Jealth Sci J. 1993;12(2):109-13.

54. Lardenoye CW, van Schooneveld MJ, Frits Treffers W, Rothova A. Grid laser photocoagulation for macular oedema in uveitis or the Irvine-Gass syndrome. Br J Ophthalmol. 1998;82(9):1013-6.

55. Querques G, Iaculli C, Delle Noci N. Intravitreal pegaptanib sodium for Irvine-Gass syndrome. Eur J Ophthalmol. 2008;18(1):138-41. 
56. Wu L, Arevalo JF, Hernandez-Bogantes E, Roca JA. Intravitreal infliximab for refractory pseudophakic cystoid macular edema: results of the Pan-American Collaborative Retina Study Group. Int Ophthalmol. 2012;32(3):235-43.

57. Pendergast SD, Margherio RR, Williams GA, Cox MS, Jr. Vitrectomy for chronic pseudophakic cystoid macular edema. Am J Ophthalmol. 1999;128(3):317-23.

\section{Corresponding author:}

Maria Fernanda Abalem

Rua Capote Valente, 171/62 - São Paulo, SP, Brasil

CEP: 05409-000.

E-mail: mfabalem@yahoo.com.br 